\title{
The Iconicity of Picture Communication Symbols for Children with English Additional Language and Mild Intellectual Disability
}

\author{
Shakila Dada, Alice Huguet, and Juan Bornman \\ Centre for Augmentative and Alternative Communication, University of Pretoria, South Africa
}

Acknowledgements

This manuscript is based on the master's dissertation completed by the second author with the first author as supervisor and the third author as co-supervisor. The authors wish to thank Dr. Jennifer Stephenson for her editorial assistance on this manuscript.

Declaration of Interest

The authors report no conflict of interest. The authors alone are responsible for the content and writing of this paper.

Correspondence concerning this manuscript should be addressed to Alice Huguet, 3 Rue Philis de la Charce, 38000, Grenoble, France, Tel : 00336012137 57; alicehuguet19@gmail.com.

\begin{abstract}
The purpose of this study was to examine the iconicity of 16 Picture Communication Symbols (PCS) presented on a themed bed-making communication overlay for South African children with English as an additional language and mild intellectual disability. The survey involved 30 participants. The results indicated that, overall, the 16 symbols were relatively iconic to the participants. The authors suggest that the iconicity of picture symbols could be manipulated, enhanced, and influenced by contextual effects (other PCS used simultaneously on the communication overlay). In addition, selection of non-target PCS for target PCS were
\end{abstract}


discussed in terms of postulated differences in terms of distinctiveness. Potential clinical implications and limitations of the study, as well as recommendations for future research, are discussed.

Keywords: English additional language (EAL); Iconicity; Intellectual disability; Picture Communication Symbols (PCS); distinctiveness; PCS modification; PCS removal; PCS replacement

\section{Introduction}

Typical communication involves the representation of meaning usually by spoken or printed words (Lloyd, Fuller, Loncke, \& Bos, 1997). However, many individuals with intellectual disabilities have little or no functional speech and cannot benefit from the use of these conventional communication methods (Mineo Mollica, 2003). The field of augmentative and alternative communication (AAC) provides these individuals with methods to create shared meaning by using aided and/or unaided symbols (Stephenson, 2009). There is a broad range of unaided and aided methods used in AAC; however, graphic symbols form a very important component of most aided AAC systems (Basson \& Alant, 2005; Fuller \& Lloyd, 1997; Fuller, Lloyd, \& Stratton, 1997; Lloyd, Fuller, Loncke, \& Boss, 1997). Choosing an appropriate graphic symbol set is one of the most important considerations when implementing AAC for individuals with little or no functional speech (Stephenson, 2009).

When deciding on a particular graphic symbol set for a potential AAC user, one of the symbol selection considerations is iconicity (Fuller \& Lloyd, 1997). Iconicity of symbols has been widely discussed in the research literature within the field. A common definition describes iconicity as a perceived relationship between a symbol and its referent, which is 
often described as a visual similarity (Blischak, Lloyd, \& Fuller, 1997; Fristoe \& Lloyd, 1979; Lloyd \& Fuller, 1990; Mizuko, 1987; Schlosser \& Sigafoos, 2002). This study uses a psycholinguistic understanding of the term iconicity in that it refers to any type of association that a viewer forms to link a symbol to its referent, not only a visual one (Schlosser \& Sigafoos, 2002). Iconicity exists on a continuum, with transparency at one end and opaqueness at the other (Lloyd \& Fuller, 1990). A symbol is considered transparent when its visual aspects are highly suggestive of its referent, and therefore the meaning can be easily determined by naïve viewers, without the provision of additional cues (Blischak et al., 1997). A symbol is seen to be translucent when the relationship between a symbol and its referent is not readily guessable, but can be perceived by naïve viewers once the referent is known (Blischak et al., 1997). The relationship is semantic, conceptual or linguistic, thus making translucency a less restrictive aspect of iconicity than transparency (Bloomberg, Karlan, \& Lloyd, 1990). When a symbol is not considered iconic, it is often referred to as opaque (Blischak et al., 1997).

The literature describes many variables that may influence the iconicity of graphic symbols. For the purpose of this manuscript, the authors have grouped these variables as symbol effects, referent effects, instructional effects, and individual effects. It is also possible that there may be interactions between these effects.

Symbol effects on iconicity may include the material on which the symbol is printed (Deregowski, 1980; Nadal, 1939), the outline shape of the symbol in relation to the referent (Dixon, 1981), the symbol's colour (Light, Drager, \& Nemser, 2004; Light, Page, Curran, \& Pitkin, 2007; Stephenson, 2007), animation of the symbol (e.g., Fujisawa, Inoue, Yamana, \& Hayashi, 2011; Schlosser, Shane, Sorce, Koul, \& Bloomfield, 2011), the symbol's motivational value (Mineo Mollica, 2003), translucency (Huang \& Chen, 2011), complexity (Koekemoer, 2000; Luftig \& Bersani, 1985), the convergence of the symbol set or system 
that it comes from (Schlosser, 1997), and its graphic symbol structure (McNaughton \& Lindsay, 1995). In Type 1 symbols, iconicity plays a role in their representation in that the symbol's elements depict the referent's salient visual features (McNaughton, 1993). These symbols are processed as a whole/gestalt or as arrays of patterns, relatively directly and without linguistic coding (McNaughton, 1993). PCS fall into this category. In Type 2 symbols, visual appearance does not play a role in symbol-referent relationships and therefore there is no dependence on visual matching (McNaughton, 1993). When defining iconicity in terms of Type 2 symbols the association between referent and symbol is made through other domains, such as the phonologic and semantic (McNaughton, 1993). Iconicity does not come into play in the processing of these Type 2 symbols. In general terms, Type 1 symbols are more iconic than Type 2 symbols (McNaughton \& Lindsay, 1995).

The second group of effects that influence the iconicity of graphic symbols is referent effects. Concreteness, or, the ease with which a referent suggests an image of that symbol, is an example of a potential referent effect (Schlosser \& Sigafoos, 2002; Yovetich \& Young, 1988). Concreteness is often affected by word class. Graphic symbols representing nouns may be more iconic than those representing other word classes (Bloomberg et al., 1990; Haupt \& Alant, 2002; Mizuko, 1987; Mizuko \& Reichle, 1989).

The third group of effects that affect iconicity is instructional effects. A number of studies have indicated the positive effects of more explicit, analytic teaching, especially for translucent/opaque graphic symbols (Emms \& Gardner, 2010; Moolman \& Alant, 1997; Schlosser \& Lloyd, 1993). Instruction assists individuals in seeing the perceptual resemblances by explaining the connection between the symbol and its referent.

The fourth group of effects is individual effects, which may influence judgment about iconicity and may include oral or literate background (Pierce \& McWilliam, 1993); schooling (Martlew \& Connolly, 1996); culture (Basson \& Alant, 2005; Haupt \& Alant, 2002; Hetzroni 
\& Harris, 1996; Huer, 2000; Nakamura, Newell, Alm, \& Waller, 1998); age (Emms \& Gardner, 2010); cognitive or thinking style (Bornman, Alant, \& Du Preez, 2009; Taylor \& Clarke, 1994; Witkin, 1967); sensorimotor functioning (Mineo Mollica, 2003), world knowledge (Light \& Lindsay, 1991); symbol experience (Stephenson \& Linfoot, 1996); and language competence (Barton et al., 2006).

Using graphic symbols to represent meaning is a relatively simple and straightforward task for adults with intact language and cognitive skills (Mineo Mollica, 2003). However, this is not the case for individuals with cognitive challenges, because they may have reduced resources in terms of world knowledge, symbol experience, and language competence to rely on when interpreting graphic representations (Mineo Mollica, 2003).World knowledge refers to an understanding of the relationships between oneself and environmental people and objects in the environment (Rowland \& Schweigert, 2003). It is based upon previous experiences and their perceived value, which will shape the expectations regarding future behaviour (Rowland \& Schweigert, 2003). World knowledge is used to successfully solve problems, perform tasks, interact with others, and participate in any type of cognitive activity (Light \& Lindsay, 1991); it is dependent on experience in and of the world (Rowland \& Schweigert, 2003). Previous experience with symbols will influence the iconicity of graphic symbols for an individual (DeLoache, 1991; Stephenson \& Linfoot, 1996). Experience with picture recognition and use assists an individual to perceive the similarity between a picture and a referent and to see this similarity as a relationship between the picture and referent (Stephenson \& Linfoot, 1996). The pivotal achievement of symbolic behaviour, termed representational insight, can be seen when children recognise some kind of a relationship between a referent and its symbol (DeLoache, 1995). Iconicity is one of the factors that influence the achievement of representational insight (Stephenson, 2009). The more a symbol 
resembles its referent, the easier it is to determine a visual relationship between the two (DeLoache, 1995).

Sevcik and Romski (1986) conducted a study into the representational matching skills of eight individuals with severe intellectual disabilities using objects, line drawings, and photographs. Half of the participants had some functional language and comprehension, whereas half did not (Sevcik \& Romski, 1986). The results showed that individuals with severe intellectual disabilities and functional language skills were able to match objects to photographs and line drawings, whereas individuals without functional language and little comprehension were not (Sevcik \& Romski, 1986). Mirenda and Locke's (1989) study compared the translucency of 11 different types of graphic symbols with participants of varying levels of severity of intellectual disability (mild-severe). The study reported that the participants with poor spoken language comprehension performed at lower levels than those with functional language. In addition, Barton et al. (2006) conducted a study with four preschool children with severe intellectual disabilities using Blissymbols and lexigrams. The results indicated no differences between the learning of opaque and comparatively iconic symbols, and that better language comprehension skills appeared to result in better symbol learning. These studies seem to suggest that improved language function increases the understanding and use of iconicity with graphic symbols. It could be that the key to making the symbol-referent association is the language comprehension skill that the individual brings to the task (Barton et al., 2006). It should be noted, though, that these studies investigated individuals with severe intellectual disabilities, while the current study focused on participants with mild intellectual disabilities.

Most iconicity studies have been conducted in European-American linguistic communities, despite growing awareness of the influence of language and culture (Huer, 2000; Beukelman \& Mirenda, 2013). Many children with disabilities in South Africa have 
diverse cultural and linguistic backgrounds, and multilingualism has increased (De Klerk, 2002). Often, these children are required to learn English when entering the formal schooling system because it is generally the language of learning and teaching (Meirim, Jordaan, Kallenbach, \& Rijhumal, 2010). Therefore, English is often not the first language but becomes an additional one in which teaching, therapy interventions, and AAC is provided (Meirim et al., 2010).

Iconicity may be influenced by diverse backgrounds, intellectual disabilities, and/or language skills, particularly an additional language. By diverse backgrounds we mean not just diversity of culture, but also diversity of exposure to literacy enriched environments or oral cultures, all of which influence typically developing children's performance in iconicity studies. Only two published iconicity studies using PCS have been conducted with South African children from diverse cultures, with both studies involving children with typical development. The present study is based on these two studies, both of which used a themed bed-making communication overlay (Haupt \& Alant, 2002; Basson \& Alant, 2005). The current study also utilized a bed-making communication overlay. Although the participants in the current study had had no prior exposure to the overlay, they were familiar with bed making as part of their activities of daily living.

Haupt and Alant (2002) investigated the accuracy of typically developing 10-year-old isiZulu-speaking children in identifying 36 PCS presented thematically on a commercially available overlay in response to labels presented in spoken isiZulu. The results indicated that isiZulu-speaking participants most often correctly identified nouns. Basson and Alant (2005) conducted a similar study on 46, 6-year-old Afrikaans-speaking children with typical development. This study investigated how accurately the participants were able to identify 16 PCS presented thematically on a commercially available overlay, in response to labels presented in spoken Afrikaans, as well as how accurately the children could recognise the 16 
symbols after exposure to a learning experience. The results indicated that the iconicity of the selected symbols was generally low on first exposure and that all of the participants also had difficulty interpreting arrows in 7 of the symbols. Participants' skills in identifying graphic symbols to a spoken gloss improved after exposure to the learning experience. Hence, both studies indicated that iconicity of the PCS was generally low (approximately $11 \%$ accuracy) for these participants and that they had difficulty interpreting the symbols involving arrows. The lower levels of iconicity in these studies foreshadowed the need for further investigation, particularly of the investigation of types of errors made by children.

The present study, therefore, aimed to determine the ability of South African children with English as an additional language and mild intellectual disabilities to select a PCS from a display of 16 symbols on a themed bed-making communication overlay when given the spoken English word. PCS were used for this study because they are readily available and used extensively in South Africa, particularly amongst school-aged children who use AAC (Bornman, Bryen, Kershaw, \& Ledwaba, 2011). The selection of a target PCS in response to a spoken label provides information on the iconicity of that symbol. Examination of the selection of a non-target PCS may provide insight into the type of errors made and enables the exploration of reasons for the errors. These insights would be achieved by determining the frequency with which symbols were selected as target and non-target symbols, and the frequency of selection of non-target symbols instead of specific target or various target PCS. The aims of the study were (a) to examine the frequency with which the PCS were selected as target symbols and non-target PCS, (b) to explore the factors that might contribute to errors, and (c) to determine the correlation between the participants' scores on English vocabulary measures and their accuracy selecting target PCS. 


\section{Method}

\section{Research Design}

A quantitative, non-experimental, descriptive design was used, based on the research designs of two similar studies (Haupt \& Alant, 2002; Basson \& Alant, 2005). Participants were required to identify target PCS out of 16 PCS from a themed bed-making communication overlay in response to a gloss read aloud by the researcher (Basson \& Alant, 2005; Haupt \& Alant, 2002).

\section{Participants}

Permission was obtained from the relevant authorities to conduct the study, and the University of Pretoria granted ethical approval. Parental consent letters were sent to parents of children who met the following selection criteria: (a) between the ages of 12 and 15 years, (b) normal hearing, (c) no reported uncorrected vision or reported visual difficulties in the classroom or home, (d) a first language other than English, (e) independently able to manipulate pen and paper, (f) attendance at an English medium school for 3 years and no direct intervention involving the use of PCS, and (g) mild intellectual disability as indicated by a composite IQ score of between 50-70 (Kaplan \& Sadock, 1998). The previous two studies had been conducted on typically developing children in their home language (which was not English). There was a need to investigate iconicity of PCS in relation to additional demands placed on the children by the cumulative effect of mild intellectual disability and English as an additional language. Because the participants in this study were able to communicate using speech, the results of the study cannot be generalized to individuals who require $\mathrm{AAC}$.

A total of 42 letters and forms requesting informed consent were distributed to parents via classroom teachers. Of these, two parents did not give consent and one reply form was not returned, resulting in 39 potential participants. These participants then completed a 
child-friendly assent procedure in which the researcher read through the assent letter with the participants, allowing time for any questions. Each aspect of the assent procedure was depicted with a PCS and the researcher pointed to these while reading the letter again. The researcher then explained the PCS for YES and NO to be used in the completion of the assent form. Finally, the researcher read each question on the assent form, allowing time for the participants to indicate either yes or no. The assent procedure lasted about $10 \mathrm{~min}$. and was video-recorded to familiarize the participants with the presence of the video camera to be used in the main data collection sessions.

Thereafter, the IQ scores and English vocabulary of the participants were assessed using the Kaufman Brief Intelligence Test, Second Edition (KBIT-2) (Kaufman \& Kaufman, 2004), the Receptive One-Word Vocabulary Picture Test (ROWPVT) (Brownell, 2000a), and the Expressive One-Word Vocabulary Picture Test (EOWPVT) (Brownell, 2000b) respectively. Nine of the potential participants did not meet the IQ selection criterion of between 50 and 70 for mild intellectual disability, resulting in 30 participants for the study, 9 girls and 21 boys. The mean chronological age was 13; 04 (years; months). All of the participants had a first language other than English. isiZulu was the most commonly spoken first language (22 participants); followed by Sepedi and Setswana (three participants each); and Sesotho and isiXhosa (one participant each). All of the participants used English as an additional language for education and had been attending the school where English was the language of learning and teaching for at least 3 years prior to the start of this research; implying that they had been exposed to English for a minimum of 3 years and were able to communicate in English for their school activities. The teacher panel reported that the vocabulary used in the overlay would be familiar to the children.

Table 1 depicts the distribution of scores obtained by the participants on the three standardized tests, namely the KBIT-2, ROWPVT, and EOWPVT. All the participants 
presented with a mild intellectual disability indicated by a composite IQ score of between 50 and 70 (Kaplan \& Sadock, 1998) as determined by the administration of the (KBIT-2). The participants had English receptive vocabulary age-equivalent scores of between $4 ; 9$ and $8 ; 10$ and English expressive vocabulary age-equivalent scores of between 3;7 and 7;7, as assessed by the ROWPVT and the EOWVPT, respectively. The majority of participants achieved an age equivalent English receptive vocabulary score of between $5 ; 0$ and 5;11 on the ROWPVT, and an age equivalent English expressive vocabulary score of between 4;0 and 5;11 on the EOWVPT. These tests were conducted in English rather than the participants' first language because standardized tests for the various languages involved did not exist. Thus, the scores reflect participants' competence in English. It cannot be empirically stated that the participants had the same level of receptive language in their first language.

Insert Table 1 here

According to information from their school records, 10 of the participants had a primary diagnosis of intellectual disability; 4 had right hemiplegic cerebral palsy; 4 had left hemiplegic cerebral palsy; one each had spastic diplegic cerebral palsy, mixed cerebral palsy, spinal muscular atrophy, epilepsy, and traumatic brain injury; and the remaining 7 did not present with any specified medical diagnoses. The physical disabilities of some of the participants did not affect their ability to complete the assessments independently. None of the participants had any sensory disabilities.

\section{Materials}

The measuring instrument used in this study was based on the themed bed-making overlays used in the studies of children with typical development by Haupt and Alant (2002) and Basson and Alant (2005). Haupt and Alant (2002) used an overlay that consisted of 36 PCS with the 10-year-old children in their study, and Basson and Alant (2005) used 16 PCS because of the younger age of their participants (6 years old). The current study also used 
only 16 PCS because the participants had mild intellectual disabilities. Based on the authors' clinical experiences and the results of Basson and Alant's (2005) study, it was held that a 36symbol overlay may have been too demanding for the participants in terms of their attention and visual scanning skills. In addition, the participants in the current study had a receptive vocabulary age equivalent score in English (an additional language) of approximately 5 years old. Though their mean chronological age was 13;4 (years;months), the age equivalent scores were comparable to those in Basson and Alant's (2005) study, where the chronological age of the children was 6 years old. The 16 symbols selected for the bed-making overlay were reviewed by both a teacher panel and a peer panel to ensure the linguistic and cultural appropriateness of the selected symbols and their glosses for the participants in this study.

The teacher panel consisted of six female participants with experience working with children with intellectual disabilities and English as an additional language. At the time of the study, all of the teachers taught children who fell in the same age range as the study participants. All of the teachers were multilingual. Two spoke English as a first language and one each spoke Afrikaans, isiZulu, isiXhosa and Sesotho as a first language. The teacher panel was provided with a questionnaire that asked them to judge each of the 16 symbols in terms of how well each symbol represented its referent/gloss; and whether or not they believed the participants would understand the vocabulary in the glosses (Huguet, 2012). The results indicated that 4 of the 16 symbols and/or their glosses required revision. Three of the four changes were symbol replacements, whereby the PCS was replaced with another that better represented the same gloss or meaning; the other was a symbol removal (see Table 2). For example, the original PCS representing the phrase, They're dirty, was replaced with a PCS that depicted dirty clothes. Similarly, the symbol for Put it in the hamper was replaced with a symbol for Put it in the washing basket. In this case, even though both the vocabulary of the gloss and the graphic were changed, the meaning remained the same, rendering this 
change a PCS replacement as opposed to a PCS removal. Some PCS and their glosses were removed entirely and exchanged for a different PCS gloss and meaning. For example, the PCS for It looks like a bomb went off was removed and replaced with a symbol for Put it on Changes to symbols and/or their glosses based on teacher-panel feedback were shown to the panel members again. Once they were satisfied, the second stage of the review process started and the symbols were shown to the peer panel for review.

The peer panel consisted of six, 9-year-old, Grade 3 children with typical development (three boys and three girls) who were multilingual and attended a government mainstream school where teaching was in English. None of these children spoke English as their first language. The peer group met the same selection criteria as those set for the participants in the main study (described above), except for the younger age range and absence of intellectual disability. The participants in the peer panel were younger than those in the main study; younger participants were selected so that their cognitive functioning more closely matched that of the study participants who had intellectual disabilities. Although the children on the peer panel were not given IQ tests, none had repeated a grade and all were considered by their teachers to have typical functioning. Three members of the peer panel spoke Setswana as their first language, two spoke Sepedi and the remaining panel member spoke siSwati. All of the participants were competent in English, which was their language of education.

During sessions with the researcher, each member of the peer panel was asked to write a sentence using the main vocabulary items in the 16 glosses, in order to ascertain if they understood these vocabulary items; and to judge each symbol in terms of the representativeness of its referent/gloss. The researcher then wrote down the sentences produced by the participants. Each session lasted approximately $20 \mathrm{~min}$, with a scripted routine used to ensure consistency in administration. One point was given to a semantically 
appropriate sentence involving the target word/phrase, which demonstrated an understanding of the word/phrase. Each word/phrase could, therefore, achieve a potential total score of 6 if all of the members of the peer panel demonstrated understanding. The words that achieved a score of 3 or less were changed. Only one achieved a score of 2, namely, pillowcase, which was changed to the pillow.

The results indicated that 7 of the 16 symbols and/or their glosses required revision: 4 were replaced, 3 were modified, and one was removed (see Table 2). PCS modification involved altering one or more aspects of a symbol without changing the overall appearance of the resulting symbol. For example, given that the participants in this study were children, the symbol for Help me please was modified from depicting two same-sized hands to one symbol depicting a smaller hand at the bottom to indicate a child's hand. Another change involved exchanging PCS stick figures for the same PCS with conventional figures. Stick figures are not commonly seen in the drawings of young children (Martlew \& Connolly, 1996), indicating that they may not be a relevant form of representation for young children or individuals with intellectual disabilities, for that matter. Conventional figures are realistic drawings of the human figure with distinctions between the head, body, and limbs (Cox, 1993).

Following the panel review, 11 of the 16 PCS were revised: 9 were replaced with other PCS available on BoardMaker ${ }^{\mathrm{TM}^{1}}$ and 2 (Help me please; It's nice and soft) were modified using the Board Maker program. Due to logistical reasons, these changes were not returned to the peer panel; however, all members of the teacher panel agreed that the changes suggested were satisfactory. The revised overlay was used in the pilot study and in the main study. Figure 1 depicts the final 16 PCS and their glosses that were used on the bed-making overlay. 


\section{Insert Figure 1}

A training and trial overlay was developed to familiarize participants with the assessment instrument and response procedures. It consisted of 16 PCS representing bird, book, throw, dog, baby, chair, cat, eat, apple, girl, toilet, shoes, hat, man, cry, and car; 3 of which were used as training items and 5 of which were trial items; the glosses for these were bird, book, throw the ball, dog, the baby is crawling, a big chair, the cat, and eat your food, respectively. The PCS foils were selected from a list of suggested vocabulary items (Fristoe \& Lloyd, 1980) for an initial sign lexicon for individuals with intellectual disabilities and other severe communication disorders.

The final measurement instrument was comprised of 8 identical pages of the training and trial overlay that were used for training purposes and 16 identical pages of the bedmaking overlay used for data collection for the study. All of the pages displayed 16 black and white PCS, presented in four rows of four on a white page $(295 \mathrm{~mm} \times 210 \mathrm{~mm})$ in portrait orientation. Each symbol was presented in a rectangle $(50 \mathrm{~mm} \times 40 \mathrm{~mm})$. No glosses were printed in the measurement instrument.

Prior to initiating the actual study, a pilot study was conducted to confirm the feasibility of the planned participant selection and consent procedures, the data collection procedures, and the suitability of the measuring instrument and test protocol. The pilot study was conducted with six participants from a different but comparable school for learners with special educational needs. Based on the results of the pilot study, only minor adaptations were required to the participant recruitment and consent procedures; no changes were made to the measurement instrument or the data collection procedures.

\section{Procedure}

The participants were met in their classrooms and escorted to the test room. Before entering the room, they were provided with a label indicating their participant number, which 
was pre-recorded on their measuring instrument to ensure that it could be matched with their English vocabulary scores, once data collection was completed. The participants were then seated at a desk with the booklet of the overlays. First, the training procedure, involving three items on the training and trial overlay, was conducted. The researcher read out the gloss and demonstrated crossing off the target PCS on the measuring instrument, which was held up for the participants to see (Haupt \& Alant, 2002). The participants were then required to mark the target symbols independently after the gloss was read out for five trial items, without modeling or any other help from the researcher.

Throughout the data collection sessions, a scripted routine was followed to enhance procedural reliability. The order in which the glosses for the PCS were read out was determined prior to the data collection sessions by randomly drawing the symbols out of a bag and assigning each a number (Haupt \& Alant, 2002). Each gloss was repeated once and participants were required to cross one symbol per page (Basson \& Alant, 2005; Haupt \& Alant, 2002). The participants were instructed to scan the symbols on each page visually before the gloss was read out (Haupt \& Alant, 2002). The researcher prompted the participants to turn the page at the correct time and ensured that each participant was on the correct page at all times. Verbal praise was provided by the researcher using non-specific comments such as Good listening, Great work, and Good job. The sessions were videorecorded for coding for procedural reliability. After the measuring instrument had been completed, each participant was given a token of appreciation (a sweet) and escorted back to class.

After each session of data collection, the researcher analyzed the responses to the trial items. Participants were required to score $100 \%$ (5 correct out of 5) for the trial items in order for their data to be used in analysis. All 30 participants met this criterion.

\section{Reliability}


A second observer viewed $40 \%$ of the video-recorded data collection sessions that were selected randomly, in order to check for procedural reliability; a checklist was used to record whether or not each step in the data collection procedure was completed accurately (McMillan \& Schumacher, 2010). Procedural reliability was calculated as the number of correctly completed steps divided by the total number of steps in the procedure, expressed as a percentage (McMillan \& Schumacher, 2010). Each data collection session had a total of 134 procedural steps and three sessions were checked by the second observer. Across these three sessions, 390 steps were correctly completed; the procedural reliability was therefore $97 \%$.

The reliability of data was assessed by the scoring of a randomly selected $40 \%$ of the completed measuring instruments by a trained second assessor (McMillan \& Schumacher, 2010). Inter-rater reliability was calculated as the number of correctly scored items divided by the total number of scored items, expressed as a percentage (McMillan \& Schumacher, 2010). The inter-rater reliability score was $99 \%$.

\section{Data Analysis}

The participants' symbol selections for each gloss were coded as selection of the target symbol (if the selected symbols matched the corresponding gloss) or a non-target symbol (if the selected symbol did not match). All of the participants made a selection for each item. The frequencies of correct selections of target PCS were calculated across participants and symbols. Descriptive statistics were used to organize and summarize the data obtained (McMillan \& Schumacher, 2010).

After all of the responses were coded, an expert panel further reviewed the selection of non-target symbols to derive insight into the pattern of errors. The expert panel consisted of three speech therapists; of whom two had postgraduate degrees in AAC. The expert panel review was conducted according to the informal, minimally structured 3-step procedure 
proposed by de Jong and Schellens (1995). First, the expert panel was provided with background information regarding the aims of the study and the measuring instrument, as well as a description of the participants and proposed types of distinctiveness. This step was necessary to counteract the possible Frame of Reference Effect (de Jong \& Schellens, 1995), which may occur if experts base their comments on personal contexts and experience and neglect to look at the "bigger picture" or the specific environments for which the instrument was intended. Second, the experts were provided with a table. The table had symbols that showed the target symbols and the same non-target symbol selected by participants, as well as the target symbols and the various non-target symbols that were selected. In addition, the table contained a column that the panel members could use to suggest the type of distinctiveness they thought may have influenced the participants' selections and provide general comments. Third, a face-to-face discussion was held and differences were discussed until consensus was reached on the most likely reasons for selection of non-target symbols. Spearman correlation coefficients (Spearman, 1904; Corder \& Foreman 2009) were computed between the number of target symbols selected by each participant and their receptive and expressive English vocabulary scores, in order to determine if there were any relationships between them.

\section{Results}

\section{Frequency of Target PCS Selections}

Figure 2 represents the frequency of correct selections of each target symbol (the symbol corresponding to the given gloss). Each symbol could have been potentially selected 30 times (once by each of the 30 participants) as a target symbol. Half of the symbols were correctly selected approximately $75 \%$ of the time, suggesting that, overall, the PCS were iconic. 
Figure 2 indicates that the participants correctly selected three symbols with a frequency of $90 \%$ (Need to pull it; Hold it please; Put it in the washing basket), and that the PCS for It's nice and clean was the least-selected, at a frequency of 33\%.

\section{Frequency of Non-Target PCS Selections}

Figure 3 depicts the frequency with which each PCS was selected when it was a nontarget symbol (i.e. an incorrect selection). Eight symbols were selected relatively frequently ( $36 \%$ or one third)) instead of the target symbol (between 22 and 9 times each). They were the symbols for Uh oh, We forgot, Put it in the washing basket, The blanket, Hold this please, The pillow, What a mess, and Let me.

\section{Insert Figure 3}

On examination of the selection of non-target symbols (errors) by the expert panel, two patterns emerged: particular non-target symbols were often selected instead of a particular target symbol, or a particular non-target symbol was selected instead of a variety of target symbols. Table 3 and Table 4 provide a summary of the non-target symbols that were selected in error instead of either a specific or a range of target symbols. These tables also show the type of error as proposed by the expert panel.

In collaboration with the authors, the expert panel members classified the errors into one of three groups: (a) errors due to perceptual indistinctiveness, where the target PCS shares visual components with a different PCS that can make them look similar; (b) errors due to semantic indistinctiveness, where the symbols do not look similar visually but may represent the same meaning/gloss as that of a different PCS used in the study; and (c) errors due to both perceptual and semantic indistinctiveness, where symbols both look similar and have the potential to represent the same meaning/gloss.

\section{Insert Table 3}


Table 3 provides a summary of the non-target symbols that were often selected instead of a particular target. For example, the symbol for The blanket was selected by $50 \%$ of the participants instead of the target symbol for The pillow. These symbols may be perceptually indistinctive, which reduced their iconicity. The symbol for The pillow was selected instead of the target symbol, The blanket, by $33.3 \%$ of participants. The symbol for Put it in the washing basket was selected instead of the target symbol for It's nice and clean by $50 \%$ of the participants. It appeared that the symbol for Put it in the washing basket was also representative of the concept clean to the participants in this study, perhaps because they assumed that this symbol depicted a washing basket full of clean clothes that were newly washed or just taken off the washing line. Both of the symbols (Put it in the washing basket; It's nice and clean) could have represented the concept clean for the participants, possibly making the symbols semantically indistinctive and emphasizing the role of contextual effects on the iconicity of graphic symbols. The iconicity of the symbols for They're dirty and What a mess may have been similarly reduced because they are possibly also semantically indistinctive; both of them could represent the concept dirty. The symbol for What a mess, was selected instead of the target symbol They're dirty by $23.3 \%$ of the participants. The symbols We forgot and Uh oh are perceptually indistinctive, in that both depict similar facial expressions and hand gestures. Furthermore, they could possibly be semantically indistinctive, in that they could both be used to depict forget. The symbol for uh oh was selected instead of the target symbol for We forgot by $50 \%$ of the participants.

\section{Insert Table 4}

Table 4 shows the non-target PCS frequently selected instead of various target symbols. The symbols for We forgot, Hold this please, and Let me were also more often selected as non-target symbols than the other symbols (18, 12 and 9 times respectively). However, they followed the second observed trend because they were selected instead of a 
number of target symbols, as opposed to just a particular one; as such, they were not the symbols that were the most frequently selected. Table 3 depicts this trend. It shows the target symbols and the non-target symbols, Hold this please, We forgot, and Let me, that were selected instead and the frequency with which these selections occurred; and provides a possible explanation for the selections in the form of a contextual effect. It is possible that the other PCS on the overlay influenced the selection.

\section{Correlation Between Vocabulary Scores and Target PCS Selections}

The Spearman correlation coefficients (Spearman, 1904; Corder \& Foreman 2009) indicated no correlation between the number of target symbols that were correctly selected by each participant and either their receptive $(p=0.5)$ or their expressive English vocabulary scores $(p=0.96)$.

\section{Discussion}

The findings suggest that it may be difficult to predict the iconicity of PCS for a given population, given the range of variables that may impact iconicity. There may be several potential hypotheses to explain the differences in the results of this study compared to previous research, including factors related to the participants and to the symbols and the context in which they were presented. Generally, the frequency with which the target symbols were selected correctly was high, with half the symbols correctly identified at least $75 \%$ of the time. It should be noted that the probability that a symbol would be correctly selected by chance was only 1 in $16(.06)$ for this study. This suggests that, overall, the symbols used on the bed-making overlay were relatively iconic to the participants. This result differed from those of previous PCS iconicity studies using South African participants, which indicated that PCS were low in iconicity for their participants, with $12.5 \%$ and $11.1 \%$ of symbols correctly identified in these previous studies (Basson \& Alant, 2005; Haupt \& Alant, 2002), respectively. 
The English vocabulary levels of the participants in the current study did not seem to influence their performance selecting the 16 symbols on the bed-making overlay. Although the participants had mild intellectual disabilities, they had an established base of language skills, as evidenced by their performance on the vocabulary assessments. Their single-word vocabulary skills, as measured by age equivalent scores, were similar to those of the children in Basson and Alant (2005) and Haupt and Alant (2002). However, the participants in the present study may have had improved representational insights as a result of exposure to more than one language along with more life experience than the younger children in the previous studies. The findings may have also been influenced by the PCS used in the study. It should be noted that many of the PCS initially selected were changed or modified in some way, based on recommendations from the review panels. These changes may have influenced results. It is interesting to note that the two symbols that were the most iconic (Need to pull it; Hold this please) were not indicated for revision in either of the panel reviews (teacher and peer) and were not changed in any way before data collection. This was also the case for the least selected iconic symbol, It's nice and clean. The panel review members (teachers and peers) did not anticipate any difficulties in understanding these symbols or their gloss. The results of the panel reviews of the original 16 symbols resulted in 11 changes: 6 PCS replacements, 2 PCS removals, and 3 PCS modifications. Of these 11 symbol changes, 5 of the revised PCS were correctly selected with a frequency of less than $75 \%$, including the PCS replacements for They're dirty $(73 \%)$, and The blanket $(60 \%)$, the removal of the symbol for, Look at this $(66 \%)$, and the symbol modifications for Help me please $(50 \%)$ and We forgot $(43 \%)$. These results suggest that in many cases the changes to the symbols did not necessarily result in high levels of iconicity for the participants.

The changes made to the symbols and their glosses may have increased the iconicity of some of the symbols, with the symbols for Put it on, What a mess, Uh oh, and Let's get the 
bed made correctly identified as target symbols at a frequency of $75 \%$ or more. However, some of the changes recommended by the panel may have resulted in confusion among the participants. For example, the symbols for Uh oh, We forgot, Put it in the washing basket, and The blanket were the most frequently selected non-target PCS, but the changes may not have resulted in symbols that were sufficiently distinct. Analysis of the non-target PCS selected indicated that there were possible contextual effects that may have influenced the selections.

The results of this study seem to suggest that the iconicity of PCS should not be determined by focusing on isolated symbols, but rather should be considered in relation to other PCS symbols that will be used on a specific communication overlay. This approach more closely replicates real-world use of PCS for communication purposes. The iconicity of PCS may be influenced by the context in which they are presented (e.g., the overlay of other symbols). In this study, the contextual effects that may have been relevant were the themed overlay, the surrounding PCS, and perceptual and semantic distinctiveness; this hypothesis is based on limited post hoc analysis of the data. Future research is required to investigate these effects in a systematic manner.

This study represents a first step towards obtaining information about the iconicity of PCS (and modified PCS) for individuals with mild intellectual disabilities and English as an additional language. The main finding was that, overall, the 16 symbols used in this study were relatively iconic to the participants. Levels of iconicity exceeded those of previous studies and may suggest that the iconicity of symbols may be enhanced by modifying them according to the age, culture, and language of the person who uses AAC. The study also postulates that the iconicity of a symbol is not an isolated phenomenon, but rather may be influenced by the distinctiveness of a symbol in relation to other symbols on the display. Furthermore, the results suggest that distinctiveness not only relates to a symbol's visual 
similarity to other symbols, but also to semantic similarities. The surrounding symbols used on a communication overlay may influence the iconicity of a graphic symbol because the symbols used on a themed overlay may be visually and/or semantically indistinct from one another.

\section{Implications for AAC Intervention}

The clinical implications of this study include suggestions that might enhance the iconicity of PCS, particularly for individuals who use AAC and/or who have frequent communication partners who are pre-literate or non-literate. It may be difficult to predict the iconicity of PCS for a given population. When using PCS to create communication overlays, particular attention should be paid to all of the symbols on the overlay, as the iconicity of a symbol should not be considered in isolation, but rather in relation to the other symbols on the overlay. PCS that are perceptually and semantically distinctive will aid in reducing ambiguity, thereby enhancing iconicity when used with other symbols on a communication overlay. Furthermore, PCS that are perceptually indistinct may be difficult to distinguish from similar symbols, especially for individuals with visual difficulties who use AAC; it is likely that many persons using AAC may have a compromised visual system (Mineo Mollica, 2003). PCS that are both perceptually and semantically indistinct are likely to be even more ambiguous, thereby reducing their iconicity. This study suggests three possible techniques for manipulating PCS to enhance their iconicity -- symbol modification, symbol replacement, and symbol removal - that may be required when it is difficult to find appropriate PCS or necessary to avoid ambiguous ones. However, it should be noted that not all of the symbol modifications made in the present study resulted in high iconicity for the modified symbols. The modification techniques were not empirically proven, and additional research is required to investigate their effects on iconicity.

\section{Limitations of the Study and Future Research Directions}


There are some limitations to this study that must be considered in interpreting the results. This study included participants who had mild intellectual disabilities and English as an additional language; they did not require AAC to communicate. Generalizability of the findings is limited by the heterogeneity of the participants in this study; furthermore, since participants did not require AAC, results cannot be generalized to all persons who use AAC. The use of a specific themed overlay may limit the generalization of the findings to the same symbols when used in other contexts (Basson \& Alant, 2005). However, in clinical practice, communication overlays are often designed around themes, thereby possibly rendering their use in research more valid, both functionally and socially (Haupt \& Alant, 2002). Moreover, it may be that the specific bed-making theme was not relevant or meaningful to some of the participants in this study. Furthermore, many of the standard PCS were modified for this study; results may not reflect the iconicity of standard PCS. There is no evidence to determine whether the particular modifications used in the study actually supported greater iconicity. A further limitation of this study is that the participants' receptive and expressive skills in their first language could not be measured using standardized tests. In addition, there were no measures of the participants' understanding of the specific bed-making vocabulary used in the study; participants may not have known some of the terms or expressions. Finally, the study investigated the iconicity of the symbols in an isolated testing situation, outside of an actual bed-making situation; these results may or may not reflect performance in a realworld situation.

Future research is required to address these limitations and further investigate factors that influence iconicity. Such research could attempt to systematically test if the modifications, replacements, and adaptations actually increase the iconicity of PCS. A comparison to participants with severe intellectual disabilities who require AAC is warranted, with a specific emphasis on analysis of the error patters that may emerge. The iconicity of 
symbols for children that are mono-lingual could be investigated. Finally, future research is required to investigate the effects of contextual factors on iconicity (e.g., studies investigating the effects of contextual factors on iconicity using overlays of symbols that vary with respect to their distinctiveness). 


\section{References}

Barton, A., Sevcik, R. A., \& Romski, M. A. (2006). Exploring visual-graphic symbol acquisition by pre-school age children with developmental and language delays. Augmentative and Alternative Communication, 22,10-20.

Basson, M., \& Alant, E. (2005). The iconicity and ease of learning of picture communication symbols: A study with Afrikaans-speaking children. The South African Journal of Communication Disorders, 52, 4-11.

Bloomberg, K., Karlan, G. R., \& Lloyd, L. L. (1990). The comparative translucency of initial lexical items represented in five graphic symbol systems and sets. Journal of Speech and Hearing Research, 33, 717-725.

Bornman, J., Alant, E., \& Du Preez, A. (2009). Translucency and learnability of Blissymbols in Setswana-speaking children: An exploration. Augmentative and Alternative Communication, 25, 287-298.

Blischak, D. M., Lloyd, L. L., \& Fuller, D. R. (1997). Terminology issues. In L. L. Lloyd, D. R. Fuller, \& H. H. Arvidson (Eds.), Augmentative and alternative communication: A handbook of principles and practices (pp. 43-47). Boston, MA: Allyn and Bacon.

Beukelman, D. R., \& Mirenda, P. (2013). Augmentative and alternative communication: Supporting children and adults with complex communication needs $\left(4^{\text {th }} \mathrm{ed}.\right)$. Baltimore, MD: Paul H Brookes.

Bornman, J., Bryen, D. N., Kershaw, P., \& Ledwaba, G. (2011). Reducing the risk of being a victim of crime in South Africa: You can tell and be heard! Augmentative and Alternative Communication, 27, 117-130.

Brownell, R. (2000a). The Receptive One-Word Picture Vocabulary Test (2nd ed.). Novato, CA: Academic Therapy Publications. 
Brownell, R. (2000b). The Expressive One-Word Picture Vocabulary Test (2 nd ed.). Novato, CA: Academic Therapy Publications.

Corder, G. W., \& Foreman D. I. (2009). Nonparametric statistics for non-statisticians: A step-by-step approach. Hoboken, NJ: Wiley

Cox, M. (1993). Children's drawings of the human figure. Hillsdale, NJ: Erlbaum.

De Klerk, V. (2002).Language issues in our schools: Whose voice counts? Part 1: The parents speak. Perspectives in Education, 20, 1-14.

Dixon, L. S. (1981). A functional analysis of photo-matching skills in severely retarded adolescents. Journal of Applied Behaviour Analysis, 14, 465-478.

de Jong, M., \& Schellens, P.J. (1995). Met het oog of de lezer. Pretesmethoden voor schrifteljik voorlichtingsmateriaal. Amsterdam: Thesis publishers

DeLoache, J. (1991). Symbolic functioning in very young children: Understanding of pictures and models. Child Development, 62, 736-752.

DeLoache, J. (1995). Early understanding and use of symbols: The model model. Current Directions in Psychological Science, 4, 109-113.

Deregowski, J. B. (1980). Perception. In H. C. Triandes, \& W. Lonner (Eds.), Handbook of cross-cultural psychology: Volume 3, Basic Processes (pp. 21-115). Boston, MA: Allyn and Bacon.

Emms, L., \& Gardner, H. (2010). Study of two graphic symbol-teaching methods for individuals with physical disabilities and additional learning difficulties. Child Language Teaching and Therapy, 26, 4-22.

Fristoe, M., \& Lloyd, L. L. (1979). Nonspeech communication. In N. R. Ellis (Ed.), Handbook of Mental Deficiency: Psychological theory and research (2 nd ed.) (pp. 401-430). New York: Lawrence Erlbaum Associates. 
Fujisawa, K., Inoue, T., Yamana, Y., \& Hayashi, H. (2011). The effect of animation on learning action symbols by individuals with intellectual disabilities. Augmentative and Alternative Communication, 27, 53-60.

Fuller, D. R., \& Lloyd, L. L. (1997). Symbol selection. In L. L. Lloyd, D. R. Fuller, \& H. H. Arvidson (Eds.), Augmentative and Alternative Communication: A handbook of principles and practices (pp. 43-47). Boston, MA: Allyn and Bacon.

Fuller, D. R., Lloyd, L. L., \& Stratton, M. M. (1997). Aided AAC symbols. In L. L. Lloyd, D. R. Fuller, \& H. H. Arvidson (Eds.), Augmentative and alternative communication: A handbook of principles and practices (pp. 43-47). Boston, MA: Allyn and Bacon.

Haupt, L., \& Alant, E. (2002). The iconicity of Picture Communication Symbols for rural Zulu children. The South African Journal of Communication Disorders, 49, 40-49.

Hetzroni, O. E., \& Harris, O. L. (1996). Cultural aspects in the development of AAC users. Augmentative and Alternative Communication, 12, 52-58.

Huang, C. H., \& Chen, M. C. (2011). Effect of translucency on transparency and symbol learning for children with and without cerebral palsy. Research in Developmental Disabilities, 32, 1829-1836.

Huer, M. B. (2000). Examining perceptions of graphic symbols across cultures: Preliminary study of the impact of culture/ethnicity. Augmentative and Alternative Communication, 16, 180-185.

Huguet, A. (2012). The iconicity of Picture Communication Symbols for children with English additional language and intellectual disabilities. University of Pretoria: Electronic Theses and Dissertations. http://upetd.up.ac.za/thesis/available/etd07152012-185754/

Kaplan, H. I., \& Sadock, B. J. (1998). Synopsis of psychiatry: Behavioural science/clinical psychiatry (8th ed.). Baltimore, MA: Lippincott Williams and Wilkins. 
Kaufman, A. S., \& Kaufman, N. L. (2004). KBIT-2 -Kaufman Brief Intelligence Test, Second Edition - Manual. Bloomington, IN: Pearson.

Koekemoer, H. (2000). The comparison of the learnability and recognition between Blissymbolics and Cyberglyphs. University of Pretoria: Electronic Theses and Dissertations. etd-05112007-074054.

Light, J., Drager, K. D R., \& Nemser, J. G. (2004). Enhancing the appeal of AAC technologies for young children: Lessons from the toy manufacturers. Augmentative and Alternative Communication, 20, 137-149.

Light, J. \& Lindsay, P. (1991). Cognitive science and augmentative and alternative communication. Augmentative and Alternative Communication, 7, 186-203.

Light, J., Page, R., Curran, J., \& Pitkin, L. (2007). Children's ideas for the design of AAC assistive technologies for young children with complex communication needs. Augmentative and Alternative Communication, 23, 274-287.

Luftig, R. L., \& Bersani, H. A., Jr. (1985). An investigation of two variables influencing Blissymbol learnability with nonhandicapped adults. Augmentative and Alternative Communication, 1, 32-37.

Lloyd, L. L., \& Fuller, D. R. (1990). The role of iconicity in augmentative and alternative communication symbol learning. In W. I. Fraser (Ed.), Key issues in mental retardation issues (pp. 295-306). London: Routledge.

Lloyd, L. L., Fuller, D. R., Loncke, F., \& Bos, H. (1997). Introduction to AAC symbols. In L. L. Lloyd, D. R. Fuller, \& H. H. Arvidson, (Eds.), Augmentative and alternative communication: A handbook of principles and practices (pp. 43-47). Boston, MA: Allyn and Bacon.

Martlew, M., \& Connolly, K. J. (1996). Human figure drawings by schooled and unschooled children in Papua New Guinea. Child Development, 67, 2743-2762. 
McMillan, J., \& Schumacher, S. (2010). Research in education: Evidence-based inquiry (7th ed.). Boston, MA: Pearson.

McNaughton, S. (1993). Graphic representational systems and literacy learning. Topics in Language Disorders, 13, 58-75

McNaughton, S., \& Lindsay, P. (1995). Approaching literacy with AAC graphics. Augmentative and Alternative Communication, 11, 212-228.

Meirim, G., Jordaan, H., Kallenbach, A., \& Rijhumal, M. (2010). Development of semantic processes for academic language in foundation phase EAL learners. South African Journal of Communication Disorders, 57, 43-50.

Mineo Mollica, B. (2003). Representational competence. In J. C. Light, D. R. Beukelman, \& J. Reichle (Eds.), Communicative competence for individuals who use AAC(pp. 107146). Baltimore, MD: Paul H. Brookes.

Mirenda, P., \& Locke, P. A. (1989). A comparison of symbol transparency in nonspeaking persons with intellectual disabilities. Journal of Speech and Hearing Disorders, 54, 131-140.

Mizuko, M. (1987). Transparency and ease of learning of symbols represented by Blissymbols, PCS, and Picsyms. Augmentative and Alternative Communication, 3, 129-136.

Mizuko, M., \& Reichle, J. (1989). Transparency and recall of symbols among intellectually handicapped adults. Journal of Speech and Hearing Disorders, 54, 627-633.

Moolman, E., \& Alant, E. (1997). The teaching of Blissymbols as a bridge into literacy for children with cognitive impairments: A comparison of two training approaches. The South African Journal of Communication Disorders, 44, 73-84. 
Nadal, S. F. (1939). The application of intelligence tests in the anthropological field. In F. C. Bartlett, E. Grinsberg, E. J. Lindgren, \& R. M. Thouless (Eds.), The study of society (pp. 184-198). London: Kegan, Paul Tyrench, Trubner and Co.

Nakamura, K., Newell, A. F., Alm, N., \& Waller, A. (1998). How do members of different language communities compose sentences with a picture-based communication system? A cross-culture study of picture-based sentences constructed by Japanese and English speakers. Augmentative and Alternative Communication, 14, 71-79.

Pierce, P. L., \& McWilliam, P. J. (1993). Emerging literacy in children with severe speech and physical impairments (SSPI): issues and possible intervention strategies. Topics in Language Disorders, 13, 47-57.

Rowland, C., \& Schweigert, P. D. (2003). Cognitive skills and AAC. In J. C. Light, D. R. Beukelman, \& J. Reichle (Eds.), Communicative competence for individuals who use AAC: From research to effective practice (pp. 241-276). Baltimore, MD: Paul H Brookes.

Schlosser, R. W. (1997). Nomenclature of category levels in graphic symbols, Part I: Is a flower a flower a flower? Augmentative and Alternative Communication, 13, 4-13.

Schlosser, R. W., \& Lloyd, L. L. (1993). Effects of initial element teaching in a story-telling context on Blissymbol acquisition and generalisation. Journal of Speech and Hearing Research, 36, 979-995.

Schlosser, R. W., Shane, H., Sorce, J., Koul, R., \& Bloomfield, E. (2011). Identifying performing and under-performing graphic symbols for verbs and prepositions in animated and static formats. Augmentative and Alternative Communication, 27, 205214. 
Schlosser, R. W., \& Sigafoos, J. (2002). Selecting graphic symbols for an initial request lexicon: Integrative view. Augmentative and Alternative Communication, 18, 102123.

Sevcik, R. A., \& Romski, M. A. (1986). Representational matching skills of persons with severe retardation. Augmentative and Alternative Communication, 2, 160-164.

Sevcik, R. A., Romski, M. A., \& Wilkinson, K. M. (1991). Roles of graphic symbols in the language acquisition process of persons with severe cognitive disabilities. Augmentative and Alternative Communication, 7, 161-170.

Spearman, C. (1904). The proof and measurement of association between two things. American Journal of Psychology, 15, 72-101.

Stephenson, J. (2007). The effect of colour on the recognition and use of line drawings by children with severe intellectual disabilities. Augmentative and Alternative Communication, 23, 44-55.

Stephenson, J. (2009). Iconicity in the development of picture skills: Typical development and implications for individuals with severe intellectual disabilities. Augmentative and Alternative Communication, 25, 187-201.

Stephenson, J., \& Linfoot, K. (1996). Pictures as communication symbols for students with severe intellectual disability. Augmentative and Alternative Communication, 12, 244255.

Taylor, O. L., \& Clarke, M. G. (1994). Culture and communication disorders. Seminars in Speech and Language, 15, 103-113.

Witkin, H. A. (1967). A cognitive styles approach to cross-cultural research. International Journal of Psychology, 2, 233-250.

Yovetich, W., \& Young, T. (1988). The effects of representativeness and concreteness on the guessability of Blissymbols. Augmentative and Alternative Communication, 4, 35-39. 


\section{End Notes}

${ }^{1}$ BoardMaker software is available from DynaVox Mayer-Johnson, 2100 Wharton Street, Pittsburgh, PA 15203, USA. http://www.mayer-johnson.com/ 
Table 1

Score Distributions of Participants on Standardized Tests

\begin{tabular}{|c|c|c|c|c|}
\hline Test & Type of Score & Score & $\begin{array}{c}\% \text { of } \\
\text { Participants }\end{array}$ & Score Range \\
\hline \multirow[t]{4}{*}{ KBIT-2 } & IQ score for mild & $50-54$ & $40 \%$ & \multirow[t]{4}{*}{$50-69$} \\
\hline & intellectual disability & $55-60$ & $34 \%$ & \\
\hline & (Kaplan \& Sadock, 1998) & $61-65$ & $13 \%$ & \\
\hline & & $66-69$ & $13 \%$ & \\
\hline \multirow[t]{5}{*}{ ROWPVT } & \multirow{5}{*}{$\begin{array}{l}\text { Age equivalent score } \\
\text { (years; months) }\end{array}$} & $04 ; 09$ & $3 \%$ & \multirow[t]{5}{*}{$04 ; 09-08 ; 10$} \\
\hline & & $\begin{array}{c}05 ; 00- \\
05 ; 11\end{array}$ & $43 \%$ & \\
\hline & & $\begin{array}{c}06 ; 00- \\
06 ; 11\end{array}$ & $38 \%$ & \\
\hline & & $\begin{array}{c}07 ; 00- \\
07 ; 11\end{array}$ & $13 \%$ & \\
\hline & & $08 ; 10$ & $3 \%$ & \\
\hline \multirow[t]{5}{*}{ EOWPVT } & \multirow[t]{5}{*}{$\begin{array}{l}\text { Age equivalent score } \\
\text { (years; months) }\end{array}$} & $\begin{array}{c}03 ; 07- \\
03 ; 11\end{array}$ & $17 \%$ & \multirow[t]{5}{*}{$03 ; 07-07 ; 07$} \\
\hline & & $\begin{array}{c}04 ; 00- \\
04 ; 11\end{array}$ & $37 \%$ & \\
\hline & & $\begin{array}{c}05 ; 00- \\
05 ; 11\end{array}$ & $37 \%$ & \\
\hline & & $\begin{array}{c}06 ; 00- \\
06 ; 11\end{array}$ & $6 \%$ & \\
\hline & & $07 ; 07$ & $3 \%$ & \\
\hline
\end{tabular}


Table 2

PCS Symbol Changes Recommended in the Panel Reviews (teacher and peer)

\begin{tabular}{|c|c|c|c|}
\hline $\begin{array}{l}\text { Original PCS symbols } \\
\text { and glosses }\end{array}$ & $\begin{array}{l}\text { Changed PCS symbols } \\
\text { and glosses }\end{array}$ & $\begin{array}{l}\text { Type of panel review that } \\
\text { resulted in change }\end{array}$ & $\begin{array}{c}\text { Type of change } \\
\text { made to PCS }\end{array}$ \\
\hline $\begin{array}{l}\text { It looks like a bomb went off } \\
\text { sivs }\end{array}$ & Put it on & Teacher panel review & $\begin{array}{l}\text { Symbol } \\
\text { removal }\end{array}$ \\
\hline $\begin{array}{l}\text { They're dirty } \\
0\end{array}$ & $\begin{array}{l}\text { They're dirty } \\
\text { 的路 }\end{array}$ & Teacher panel review & $\begin{array}{l}\text { Symbol } \\
\text { replacement }\end{array}$ \\
\hline Put it in the hamper & $\begin{array}{l}\text { Put it in the washing } \\
\text { basket } \\
\end{array}$ & Teacher panel review & $\begin{array}{l}\text { Symbol } \\
\text { replacement }\end{array}$ \\
\hline It's nice and soft & It's nice and soft & Teacher panel review & $\begin{array}{l}\text { Symbol } \\
\text { replacement }\end{array}$ \\
\hline The blanket & The blanket & Peer panel review & $\begin{array}{l}\text { Symbol } \\
\text { replacement }\end{array}$ \\
\hline Uh oh & Uh oh & Peer panel review & $\begin{array}{l}\text { Symbol } \\
\text { replacement }\end{array}$ \\
\hline It looks bad & $\begin{array}{l}\text { Look at this } \\
\text { बه }\end{array}$ & Peer panel review & $\begin{array}{l}\text { Symbol } \\
\text { removal }\end{array}$ \\
\hline $\begin{array}{l}\text { What a mess } \\
\square s\end{array}$ & What a mess & Peer panel review & $\begin{array}{l}\text { Symbol } \\
\text { replacement }\end{array}$ \\
\hline $\begin{array}{l}\text { Let's get the bed made } \\
\text { and }\end{array}$ & $\begin{array}{l}\text { Let's get the bed made } \\
\text { son }\end{array}$ & Peer panel review & $\begin{array}{l}\text { Symbol } \\
\text { modification }\end{array}$ \\
\hline $\begin{array}{l}\text { Help me please } \\
\end{array}$ & Help me please & Peer panel review & $\begin{array}{l}\text { Symbol } \\
\text { modification }\end{array}$ \\
\hline $\begin{array}{l}\text { We forgot } \\
\bigcirc_{9}\end{array}$ & $\begin{array}{l}\text { We forgot } \\
O P\end{array}$ & Peer panel review & $\begin{array}{l}\text { Symbol } \\
\text { modification }\end{array}$ \\
\hline
\end{tabular}


Table 3

Non-Target PCS Symbols Frequently Selected Instead of Specific Target PCS Symbols

\begin{tabular}{|c|c|c|c|c|c|}
\hline $\begin{array}{l}\text { Frequently } \\
\text { selected non- } \\
\text { target PCS } \\
\text { symbol }\end{array}$ & $\begin{array}{l}\text { Frequently } \\
\text { selected } \\
\text { non-target } \\
\text { gloss }\end{array}$ & Target gloss & $\begin{array}{c}\text { Target PCS } \\
\text { symbol }\end{array}$ & $\begin{array}{c}\% \text { Non-target } \\
\text { PCS } \\
\text { symbol selected }\end{array}$ & $\begin{array}{c}\text { Possible } \\
\text { explanation/ } \\
\text { contextual effect }\end{array}$ \\
\hline & $\begin{array}{l}\text { The } \\
\text { blanket }\end{array}$ & The pillow & & $\begin{array}{c}50 \% \\
(n=15)\end{array}$ & $\begin{array}{l}\text { Perceptually } \\
\text { indistinctive }\end{array}$ \\
\hline & $\begin{array}{l}\text { Put it in the } \\
\text { washing } \\
\text { basket }\end{array}$ & $\begin{array}{l}\text { It's nice and } \\
\text { clean }\end{array}$ & & $\begin{array}{c}50 \% \\
(n=15)\end{array}$ & $\begin{array}{l}\text { Semantically } \\
\text { indistinctive }\end{array}$ \\
\hline & Uh oh & We forgot & & $\begin{array}{c}50 \% \\
(n=15)\end{array}$ & $\begin{array}{l}\text { Perceptually \& } \\
\text { semantically } \\
\text { indistinctive }\end{array}$ \\
\hline & The pillow & The blanket & & $\begin{array}{c}33.3 \% \\
(n=10)\end{array}$ & $\begin{array}{l}\text { Perceptually } \\
\text { indistinctive }\end{array}$ \\
\hline & $\begin{array}{l}\text { What a } \\
\text { mess }\end{array}$ & They're dirty & 25 & $\begin{array}{l}23.3 \% \\
(n=7)\end{array}$ & $\begin{array}{l}\text { Semantically } \\
\text { Indistinctive }\end{array}$ \\
\hline
\end{tabular}


Table 4

\section{Non-Target PCS Frequently Selected Instead of Various Target PCS Symbols}

\begin{tabular}{|c|c|c|c|c|c|}
\hline $\begin{array}{l}\text { Non-target } \\
\text { PCS symbol }\end{array}$ & $\begin{array}{l}\text { Non-target } \\
\text { gloss }\end{array}$ & Target gloss & $\begin{array}{l}\text { Target } \\
\text { PCS symbol }\end{array}$ & $\begin{array}{l}\% \text { Non-target } \\
\text { PCS symbol } \\
\text { selected }\end{array}$ & $\begin{array}{l}\text { Possible } \\
\text { explanation/ } \\
\text { contextual effect }\end{array}$ \\
\hline & \multirow{7}{*}{ We forgot } & $\begin{array}{l}\text { Help me } \\
\text { please }\end{array}$ & s & $\begin{array}{l}16.7 \% \\
(n=5)\end{array}$ & $\begin{array}{l}\text { Semantically } \\
\text { indistinctive }\end{array}$ \\
\hline & & Uh oh & mop & $\begin{array}{l}13.8 \% \\
(n=4)\end{array}$ & $\begin{array}{l}\text { Perceptually and } \\
\text { semantically } \\
\text { indistinctive }\end{array}$ \\
\hline & & $\begin{array}{l}\text { Let's get the } \\
\text { bed made }\end{array}$ & 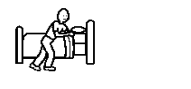 & $\begin{array}{c}10 \% \\
(n=3)\end{array}$ & Uncertain \\
\hline & & Look at this & बक & $\begin{array}{c}6.7 \% \\
(n=2)\end{array}$ & Uncertain \\
\hline & & Let me & 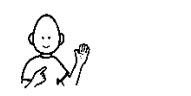 & $\begin{array}{c}6.7 \% \\
(n=2)\end{array}$ & $\begin{array}{l}\text { Perceptually } \\
\text { indistinctive }\end{array}$ \\
\hline & & Need to pull it & & $\begin{array}{l}3.3 \% \\
(n=1)\end{array}$ & Uncertain \\
\hline & & Put it on & (间) & $\begin{array}{c}3.3 \% \\
(n=1)\end{array}$ & Uncertain \\
\hline & \multirow{6}{*}{$\begin{array}{l}\text { Hold this } \\
\text { please }\end{array}$} & Looks good & 鱼 & $\begin{array}{l}13.3 \% \\
(n=4)\end{array}$ & $\begin{array}{l}\text { Semantically } \\
\text { indistinctive }\end{array}$ \\
\hline & & $\begin{array}{l}\text { It's nice and } \\
\text { clean }\end{array}$ & 回 & $\begin{array}{l}6.7 \% \\
(n=2)\end{array}$ & $\begin{array}{l}\text { Semantically } \\
\text { indistinctive }\end{array}$ \\
\hline & & $\begin{array}{l}\text { Help me } \\
\text { please }\end{array}$ & & $\begin{array}{c}6.7 \% \\
(n=2)\end{array}$ & $\begin{array}{l}\text { Semantically } \\
\text { indistinctive }\end{array}$ \\
\hline & & Look at this & (ब) & $\begin{array}{c}6.7 \% \\
(n=2)\end{array}$ & $\begin{array}{l}\text { Semantically } \\
\text { indistinctive }\end{array}$ \\
\hline & & $\begin{array}{l}\text { Let's get the } \\
\text { bed made }\end{array}$ & 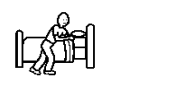 & $\begin{array}{c}3.3 \% \\
(n=1)\end{array}$ & Uncertain \\
\hline & & Need to pull it & $\Delta 0$ & $\begin{array}{l}3.3 \% \\
(n=1)\end{array}$ & $\begin{array}{l}\text { Semantically } \\
\text { indistinctive }\end{array}$ \\
\hline \multirow{5}{*}{ 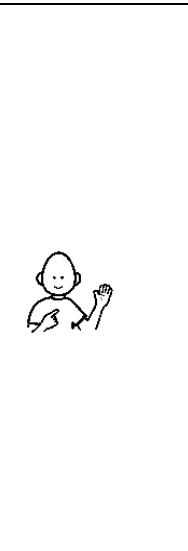 } & \multirow{5}{*}{ Let me } & $\begin{array}{l}\text { Help me } \\
\text { please }\end{array}$ & 8 & $\begin{array}{c}10 \% \\
(n=3)\end{array}$ & $\begin{array}{l}\text { Semantically } \\
\text { indistinctive }\end{array}$ \\
\hline & & Look at this & बंब ब(ब) & $\begin{array}{c}10 \% \\
(n=3)\end{array}$ & $\begin{array}{l}\text { Semantically } \\
\text { indistinctive }\end{array}$ \\
\hline & & Put it on & 畺 & $\begin{array}{c}3.3 \% \\
(n=1)\end{array}$ & Uncertain \\
\hline & & $\begin{array}{l}\text { It's nice and } \\
\text { clean }\end{array}$ & 他 & $\begin{array}{c}3.3 \% \\
(n=1)\end{array}$ & Uncertain \\
\hline & & We forgot & $\bigcirc P$ & $\begin{array}{c}3.3 \% \\
(n=1)\end{array}$ & $\begin{array}{l}\text { Perceptually } \\
\text { indistinctive }\end{array}$ \\
\hline
\end{tabular}


Figure Captions

Figure 1: The 16 PCS and glosses used for the bed-making overlay.

Figure 2: The percentage of target PCS selected $(n=30)$.

Figure 3: The selection frequency of non-target PCS. 


Lut it on

Figure 1 


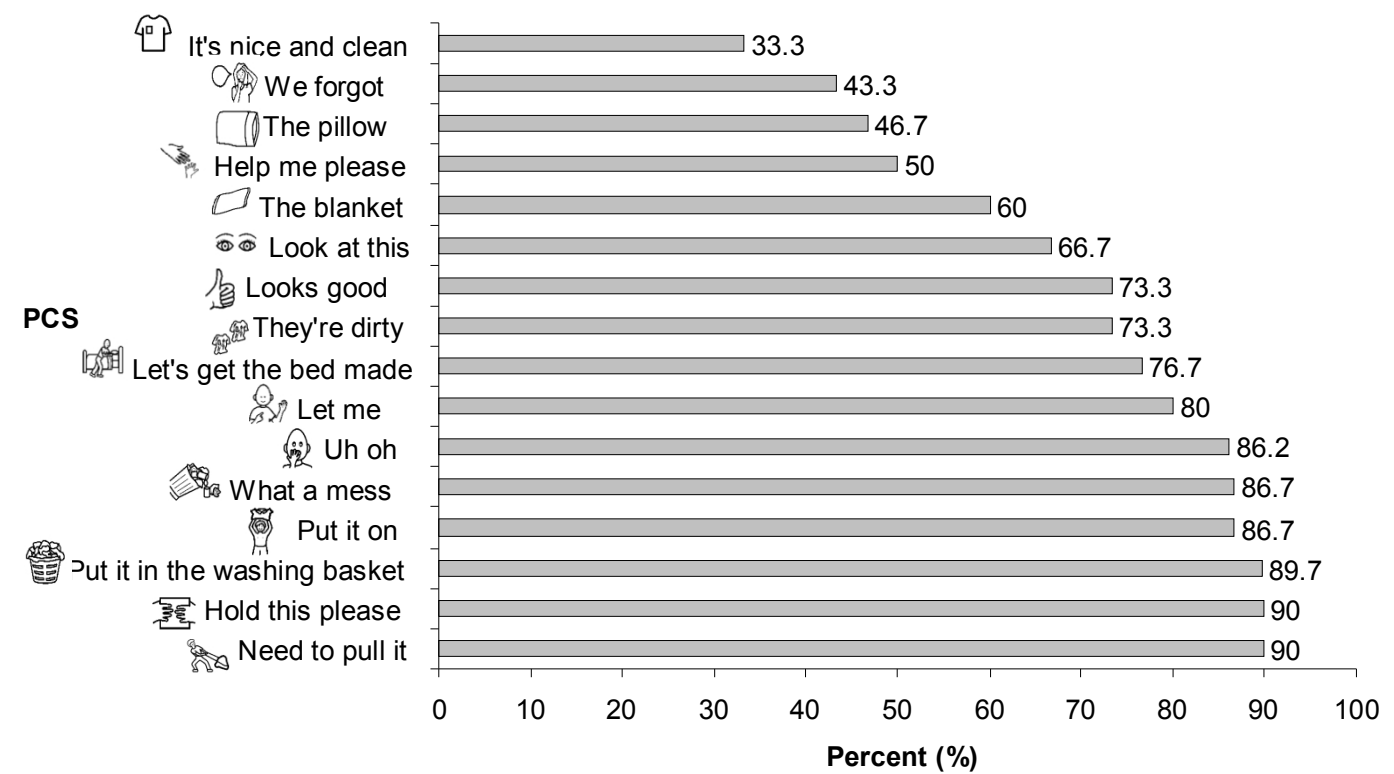

Figure 2 


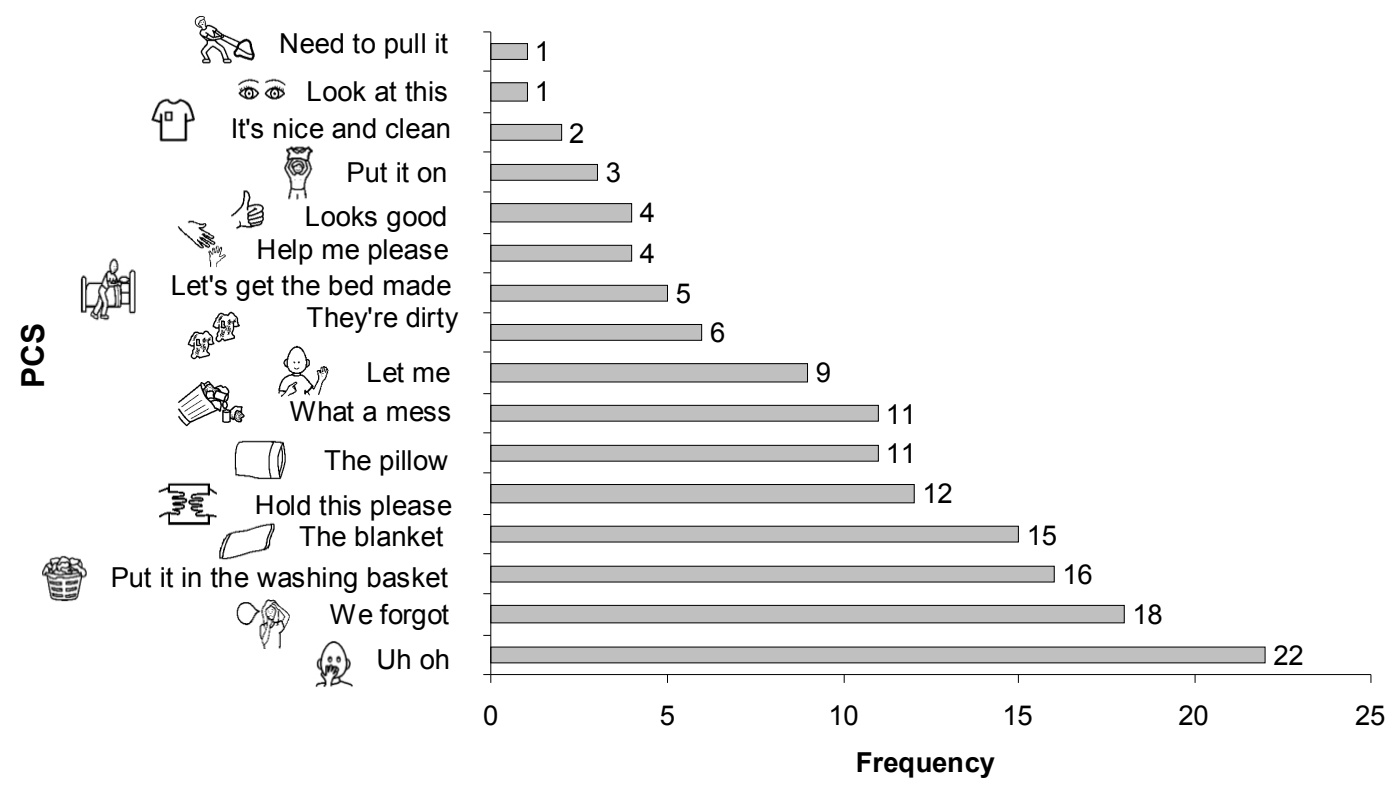

Figure 3 